\title{
USE OF AGROINDUSTRIAL WASTE AS SUBSTRATES FOR THE CULTIVATION OF EDIBLE MUSHROOMS IN THE DOMINICAN REPUBLIC
}

\author{
Héctor Rafael Peralta, MSc. Agripina Ramírez, Ph, D. Máximo Mejía, MSc. Alejandra Omarini, Ph, D. Ing. \\ Carmen Maria De Jesús and Lic. Aina Ramírez \\ Institute of Innovation in Biotechnology and Industry (IIBI). P. O. Box 329-2. Santo Domingo. Dominican Republic. \\ Ministry of Higher Education, Science and Technology (MESCYT)/ National Fund for Innovation in Scientific and \\ Technological Development (FONDOC YT)
}

https://doi.org/10.35410/IJAEB.2020.5526

\begin{abstract}
In the Dominican Republic there is a great development of agrarian and agro-industrial activity, generating quantities of chemical waste that give rise to an environmental problem. Edible mushroom cultivation has enormous potential to solve this problem. This potential is both in the production of edible mushrooms with optimal nutritional properties, and in obtaining bioactive products, helping to increase the country's economy and environmental decontamination. Four strains of edible fungi and four substrates with their combinations were used in this investigation. According to the statistical analyzes of the Cane Bagasse and Coconut Cachaça substrates, they obtained the highest colonization percentages (79.33 and 76.25\%). With the PFL-216 strain, the highest sprout yield was obtained (10.12), while in the substrates used; G + BC obtained the highest number of sprouts (11.42). The highest yield of fungi $(88.43 \mathrm{~g})$ was obtained with sugarcane Bagasse, in the same way in the strain $\mathrm{x}$ substrate interaction the highest yield was obtained with the strain PSA-224 and the sugarcane Bagasse with $126.78 \mathrm{~g}$. The strain PFL-216 and PSA-224 were adapted to the controlled environmental conditions of the research with a higher biological efficiency than the other treatments (47.23 and $42.22 \mathrm{~g})$. The substrates generated from the agro-industry are considered as a good option to be used in the cultivation of edible fungi, especially the combinations between them due to the greater production of affected carpophores, as well as the biological efficiency.
\end{abstract}

Keywords: Mushrooms, seed, strain, inoculation, incubation.

\section{INTRODUCTION}

Agroindustrial processes generate a large amount of waste that is generally accumulated in the environment, being able to contaminate it or burn it, generating toxic gas emissions (Zheng \& Shetty, 2000). This organic matter causes inconveniences to the environment: it takes up a lot of space, its natural degradation is slow and almost impossible in the volumes it generates. When these wastes are not reused and are abandoned in the place where they were generated, they contaminate soils and groundwater, becoming an environmental problem. On the other hand, these wastes abandoned in the open air without any prior treatment are considered as hazardous 
Vol. 5, No. 04; 2020

ISSN: $2456-8643$

waste, due to the presence and proliferation of infectious agents that cause harm to humans and animals, in addition to deteriorating the quality of soil, water and air ( Saval, 2012).

The few alternatives, from the economic, social and nutritional point of view, that are currently presented for the use of agro-industrial waste, together with the lack of awareness in the protection of the environment, cause them to be mismanaged and become sources of contamination of natural resources (CPTS, 2003) cited by Cury and Col; (2017). To counteract the harmful effects that its accumulation produces, several biotechnological ventures have been developed that use the waste for the production of alcohol, enzymes, organic acids and edible fungi, generating products with economic value and thus contributing to caring for the environment (Baldrian \& Valásková, 2008).

Biotechnological processes are being widely considered by industries as an alternative for the generation of goods and services, transforming the waste generated into useful products, and in this way using its potential through bioprocesses. Within this context, edible mushrooms play an important role in the bioconversion process, since they are capable of reducing large amounts of waste, minimizing contamination, and forming products of interest to the food, paper, and pharmaceutical industries, among others (Nevárez Quiñones, 2012).

Man began to feed on mushrooms since ancient times; the Romans saw them as the "food of the gods", the Chinese as "elixir of life", the indigenous Mexicans used them as hallucinogens in religious festivals and for therapeutic purposes. Mushroom cultivation started 2,000 years ago, it is believed that the first mushroom was cultivated in China in $600 \mathrm{BC}$. The most cultivated mushrooms worldwide are Agaricus bisporus (mushroom), Pleurotus ostreatus (mushroom) and shiitake (Lentinula edodes). The cultivation of edible mushrooms is an ecological biocorversion system, since what is of little use to man and which he discards, such as straws, bagasse, husks and pulps, the mushrooms transform into protein food and merchandise for sale. In addition, once the edible product has been obtained, organic fertilizer can be obtained from the residual substrate through composting and vermicomposting processes for the production of plants and vegetables; given the direct effect on the conservation and improvement of soil quality. This production alternative has been successfully exploited for a long time in other countries, mainly in Asia, where a whole technology has been developed for the production and preservation of edible mushrooms such as mushrooms, oyster mushrooms and Shiitake. Viniegra (1990) cited by Nevárez Quiñones, (2012).

The cultivation of mushrooms has potential in biotechnological applications both in the production of mushrooms and foods with optimal nutritional qualities and in obtaining bioactive products to contribute to the country's economy and environmental decontamination. The importance of fungi in human food lies in their dietary value (low carbohydrate and fat content), significant protein content (20-40\% of the dry weight) and vitamins, which places them above the majority of vegetables, fruits and vegetables. Additionally, they turn out to be delicious complements in meals due to their organoleptic properties. Fungi are a valuable source of nutrients and bioactive compounds that are responsible for their medicinal properties, such as antioxidant capacity, immunomodulatory, anticancer, antiglycemic and hepatoprotective properties, among others (Ramos, 2015). 
Vol. 5, No. 04; 2020

ISSN: $2456-8643$

International experience in the cultivation of edible mushrooms allows the community to provide this production food alternative, taking into account that using low-cost technologies adapted to the climate, agricultural resources and economic conditions would strengthen the potential of the fungi in the national level (Cury and Col; 2017). In this research, agricultural and agro-industrial residues will be used as substrates for the cultivation of edible fungi Pleurotus sapidus, Pleurotus florida.

\section{MATERIALS AND METHODS}

\subsection{Research Location}

The research was carried out both at the main headquarters of the Institute for Innovation in Biotechnology and Industry (IIBI) and at the Plant Biotechnology Center (CEBIVE) located in Pantoja and belonging to said institution. In the first, isolations and multiplication of pure cultures of the fungal species used were carried out. At CEBIVE, establishments were made for the production of edible mushrooms under controlled environmental conditions. The Research and Transfer Center of Entre Ríos (CITER) CONICET-UNER of Argentina, represented by Dr. Alejandra Omarini who advised said research, was also involved in this investigation.

\subsection{Culture media}

The culture medium for the growth and propagation of the mycelia was Malt Extract Agar (AEM): agar, $20 \mathrm{~g}$; malt extract, $12 \mathrm{~g}$; glucose, $10 \mathrm{~g}$ (Omarini and Col; 2009). To the culture medium, distilled water was added until completing 1 liter and it was sterilized in an autoclave at $121^{\circ} \mathrm{C}$, for $20 \mathrm{~min}$. The Pleurotus strains were donated by the Entre Ríos Research and Transfer Center of CONICET in Argentina. Wheat seeds were inoculated in jars weighing approximately $460 \mathrm{~g}$ of wheat with pieces of mycelium taken from the Pleurotus culture plates.

\subsection{Substrate preparation}

The materials evaluated were four agro-industrial residues, sawdust, corn bagasse, grass and coconut cachaça, which were crushed and packed in polyethylene bags each containing $15 \mathrm{~kg}$ of substrate. $2 \%$ calcium carbonate was added to each substrate bag to be sterilized by hand in a 55 gallon tank of water. For this purpose, a wood stove was used in which each substrate was boiled separately for 30 minutes in order to eliminate microorganisms that could affect the culture. The substrates were weighed in polypropylene bags containing $454 \mathrm{~g}$, then they were homogeneously inoculated with the wheat seeds containing the fungal strains (approximately $48 \mathrm{~g}$ per bag), which were sealed and a piece of cotton was placed to allow entry of oxygen and incubated at 25

${ }^{\circ} \mathrm{C}$ in the dark until the mycelium of each strain completely invaded the substrates.

\subsection{Substrates incubation}

The inoculation of the substrates was carried out in a closed room with an average temperature of 24 to $26^{\circ} \mathrm{C}$ and a relative humidity range between $70-80 \%$. The substrate covers of the different agro-industrial wastes evaluated were randomly distributed within the room on each of the shelves. To obtain the conditions required by the Pleurotus, they were kept under darkness until 
fruiting began. To ensure adequate humidity, irrigation was carried out three times a day. The variables were monitored daily with a thermohygrometer.

\subsection{Fructification}

The temperature was maintained between 24 to $25^{\circ} \mathrm{C}$ with a relative humidity range of $70-80 \%$. Light was supplied using fluorescent light over a period of 8 to 12 hours daily.

\subsection{Harvest}

The harvest was carried out at the moment when the fungi reached their maximum size. This was done in the morning before giving the first watering of the day, registering the key to the treatment and the weight of the fungi in grams. The harvest point of the mushrooms was taken when the pileo was almost flat. Three harvests were obtained, at 17, 21 and 24 days, observing a decrease in the quantity of the mushrooms produced, which were weighed on a precision balance.

\subsection{Experimental Design}

A completely randomized experimental design with a $4 \times 4$ factorial arrangement (4 fungal strains and 4 substrates) with 6 replicates randomly distributed per treatment and 3 replications per control was used.

\subsection{Treatments}

Four time trials were performed, one for each strain separately with 10 treatments each and 9 replicates ( 6 for treatment with the mushroom strain and 3 for control without mushroom strain) with 90 experimental units per test for a total of 360 experimental units including controls and 240 experimental units with fungal strains and without controls (Table 1).

Table 1. Scheme of treatments in the Production of Edible Mushrooms.

\begin{tabular}{|l|l|l|l|l|}
\hline Treatment & Sustrate & Weight(g) & Percentage & $\begin{array}{l}\text { Mushroom } \\
\text { Strain }\end{array}$ \\
\hline T1 & Grama (G) & 454 & $100 \%$ & PO \\
\hline T2 & $\begin{array}{l}\text { Cane Bagasse } \\
\text { (BC) }\end{array}$ & 454 & $100 \%$ & PO \\
\hline T3 & Sawdust (A) & 454 & $100 \%$ & PO \\
\hline T4 & $\begin{array}{l}\text { Coconut } \\
\text { Cachaça (CC) }\end{array}$ & 454 & $100 \%$ & PO \\
\hline T5 & Grama (G) & 454 & $100 \%$ & PSA-224 \\
\hline T6 & Cane Bagasse & 454 & $100 \%$ & PSA-224 \\
\hline
\end{tabular}


Vol. 5, No. 04; 2020

ISSN: $2456-8643$

\begin{tabular}{|l|l|l|l|l|}
\hline & $(B C)$ & & & \\
\hline T7 & Sawdust (A) & 454 & $100 \%$ & PSA-224 \\
\hline T8 & $\begin{array}{l}\text { Cane Bagasse } \\
\text { (BC) }\end{array}$ & 454 & $100 \%$ & PSA-224 \\
\hline T9 & Grama (G) & 454 & $100 \%$ & PFL-216 \\
\hline T10 & $\begin{array}{l}\text { Cane Bagasse } \\
\text { (BC) }\end{array}$ & 454 & $100 \%$ & PFL-216 \\
\hline T11 & Sawdust (A) & 454 & $100 \%$ & PFL-216 \\
\hline T12 & $\begin{array}{l}\text { Coconut } \\
\text { Cachaça (CC) }\end{array}$ & 454 & $100 \%$ & PFL-216 \\
\hline T13 & Grama (G) & 454 & $100 \%$ & PSA-69 \\
\hline T14 & $\begin{array}{l}\text { Cane Bagasse } \\
\text { (BC) }\end{array}$ & 454 & $100 \%$ & PSA-69 \\
\hline T15 & Sawdust (A) & 454 & $100 \%$ & PSA-69 \\
\hline T16 & $\begin{array}{l}\text { Coconut } \\
\text { Cachaça (CC) }\end{array}$ & 454 & $100 \%$ & PSA-69 \\
\hline T17 & (G+BC) & $227+227$ & $50 \%$ y 50\% & PO \\
\hline T18 & (G+A) & $227+227$ & $50 \%$ y 50\% & PO \\
\hline T19 & (G+CC) & $227+227$ & $50 \%$ y 50\% & PO \\
\hline T20 & (BC+CC) & $227+227$ & $50 \%$ y 50\% & PO \\
\hline T21 & (A+CC) & $227+227$ & $50 \%$ y 50\% & PO \\
\hline T22 & (G+BC) & $227+227$ & $50 \%$ y 50\% & PSA-224 \\
\hline T23 & (G+A) & $227+227$ & $50 \%$ y 50\% & PSA-224 \\
\hline T24 & (G+CC) & $227+227$ & $50 \%$ y 50\% & PSA-224 \\
\hline T25 & (BC+CC) & $227+227$ & $50 \%$ y 50\% & PSA-224 \\
\hline T26 & (A+CC) & $227+227$ & $50 \%$ y 50\% & PSA-224 \\
\hline T27 & $227+227$ & $50 \%$ y 50\% & PFL-216 \\
\hline
\end{tabular}


International Journal of Agriculture, Environment and Bioresearch

Vol. 5, No. 04; 2020

ISSN: 2456-8643

\begin{tabular}{|l|l|l|l|l|}
\hline T28 & $(\mathrm{G}+\mathrm{A})$ & $227+227$ & $50 \%$ y 50\% & PFL-216 \\
\hline T29 & $(\mathrm{G}+\mathrm{CC})$ & $227+227$ & $50 \%$ y $50 \%$ & PFL-216 \\
\hline T30 & $(\mathrm{BC}+\mathrm{A})$ & $227+227$ & $50 \%$ y $50 \%$ & PFL-216 \\
\hline T31 & $(\mathrm{BC}+\mathrm{CC})$ & $227+227$ & $50 \%$ y $50 \%$ & PFL-216 \\
\hline T32 & $(\mathrm{A}+\mathrm{CC})$ & $227+227$ & $50 \%$ y $50 \%$ & PFL-216 \\
\hline T33 & $(\mathrm{BC}+\mathrm{A})$ & $227+227$ & $50 \%$ y 50\% & PO \\
\hline T34 & $(\mathrm{BC}+\mathrm{A})$ & $227+227$ & $50 \%$ y 50\% & PSA-224 \\
\hline T35 & $(\mathrm{G}+\mathrm{BC})$ & $227+227$ & $50 \%$ y 50\% & PSA-69 \\
\hline T36 & $(\mathrm{G}+\mathrm{A})$ & $227+227$ & $50 \%$ y 50\% & PSA-69 \\
\hline T37 & $(\mathrm{G}+\mathrm{CC})$ & $227+227$ & $50 \%$ y 50\% & PSA-69 \\
\hline T38 & $(\mathrm{BC}+\mathrm{A})$ & $227+227$ & $50 \%$ y $50 \%$ & PSA-69 \\
\hline T39 & $(\mathrm{BC}+\mathrm{CC})$ & $227+227$ & $50 \%$ y $50 \%$ & PSA-69 \\
\hline T40 & $(\mathrm{A}+\mathrm{CC})$ & $227+227$ & $50 \%$ y $50 \%$ & PSA-69 \\
\hline
\end{tabular}

$\mathrm{PO}=$ Pleurotus ostreatus, PFL-216=Pleurotus florida, PSA-224=Pleurotus sapidus, PSA-69= Pleurotus florida+ Pleurotus sapidus

\subsection{Variables}

By direct observation, the percentage of colonization of the fungus mycelium in all the bags was quantified. Ripe fruitings were collected, the number of shoots were quantified, and production and quality parameters such as: the fresh weight of the fruit bodies and the biological efficiency (EB) were recorded.

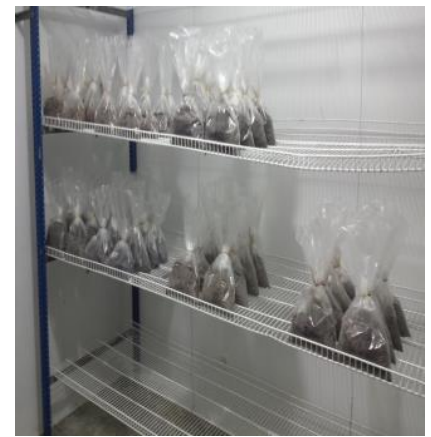

A: Incubation

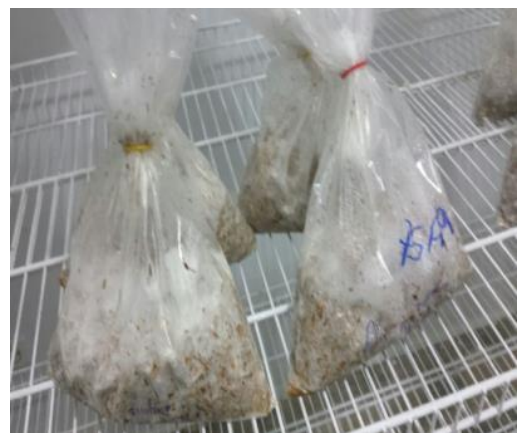

B: Colonization

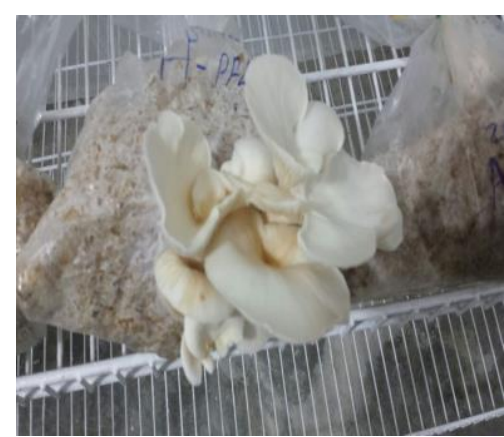

C: Production 


\subsection{Statistical analysis}

All the data were analyzed using the INFOSTAT program, version 12 (Faculty of Agricultural Sciences, National University of Córdoba). Analysis of variance was performed with the Tukey test $(\mathrm{P}=0.05)$ to detect significant differences between the means for the variables studied.

\section{RESULTS AND DISCUSSION}

\subsection{Temperature}

According to the records, the average temperature during incubation was $24.8^{\circ} \mathrm{C}$ and during fruiting $23^{\circ} \mathrm{C}$. According to the literature, the optimal temperature during the incubation time is $24-25^{\circ} \mathrm{C}$ and in fruiting it is $18-23^{\circ} \mathrm{C}$ (Soto, 2004); indicating the favorability of the place where the production of the fungus was carried out, he presented the necessary temperature conditions for its development.

\subsection{Colonization percentages}

Three days after inoculation of the substrates with the different fungal strains, the percentage of colonization was visually observed. According to the analysis of variance, the evaluated fungus strains were significantly similar to each other, except for P. ostreatus, which obtained the lowest percentage of colonization in the substrates (Annex 1). In Tukey's test the strains PFL-216 (Pleurotus florida), PSA-69 (P. florida + P. Sapidus) and PSA-224 (Pleurotus sapidus) presented similar colonization means with $71.05 \%, 66.35$ and $66.13 \%$, respectively, while the one that obtained the lowest percentage of colonization was Pleurotus ostreatus with 44.38 (Figure 3.1).

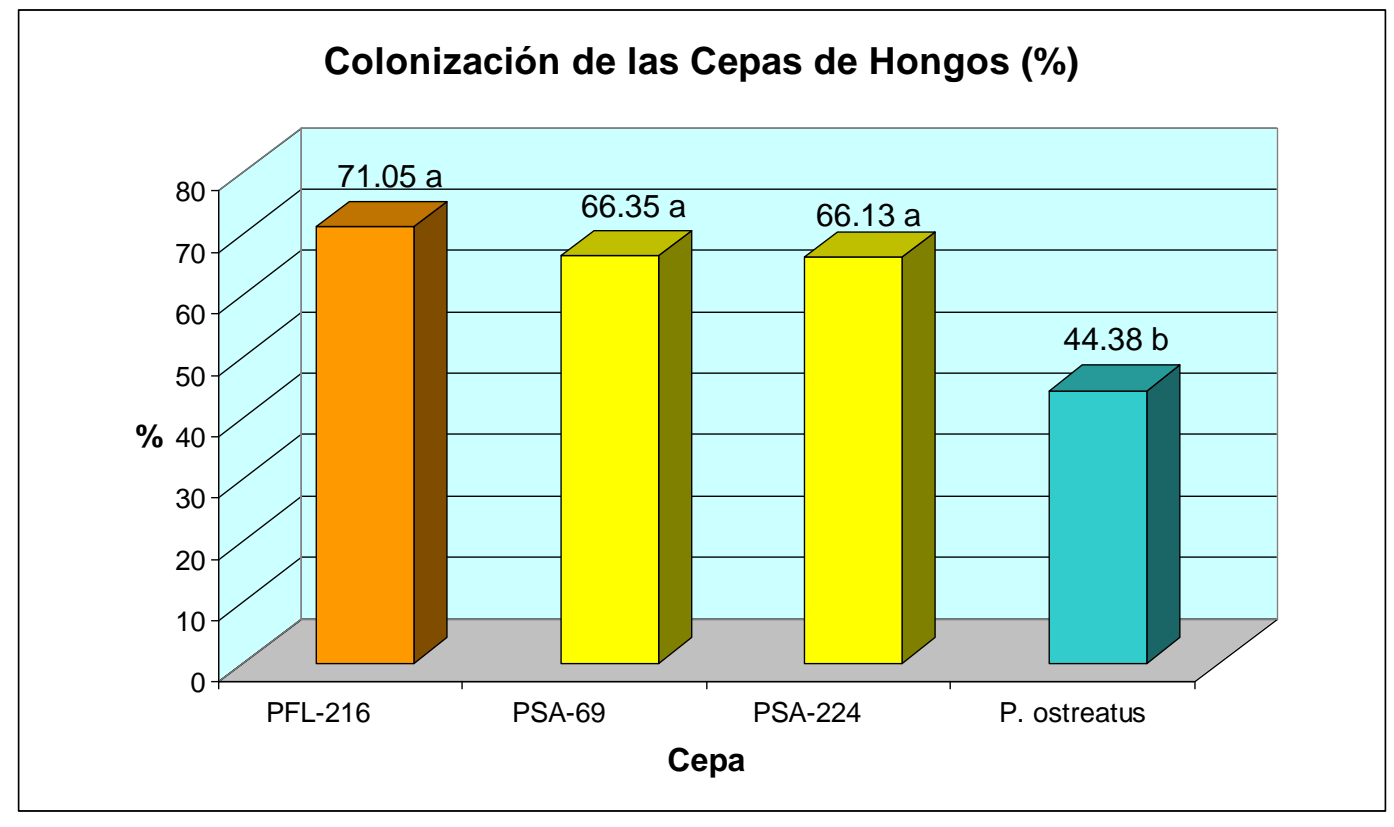

Averages with a common letter are not significantly different $(\mathrm{p}>0.05)$. 
PFL-216=Pleurotus florida PSA 224=Pleurotus sapidus PSA-69=P. florida+P. sapidus

Figure 3.1. Colonization Percentage of Edible Mushroom Strains.

Cane Bagasse and Coconut Cachaça substrates obtained the highest colonization percentages (79.33 and $76.25 \%)$. The other substrates obtained statistically similar means except for the substrates Sawdust and Bagasse of Cane + Cachaça de Coco that obtained the lowest colonization percentages of 44.98 and $44.66 \%$. (Figure 3.2) Pleurotus mushroom species possess a complex enzymatic capacity that allows them to degrade large polymers such as lignin and cellulose (Iriarte, 2003), results that coincide with what Bermúdez, García and Mourlot (2007) report, cited by Rivera and Cabbage; (2013), who reveal that the most colonized substrates of the fungus Pleurotus ostreatus are those with the highest content of structural carbohydrates (lignin, cellulose and hemicellulose), found in corn and bran (Ríos, Hoyos \& Mosquera, 2010; Vargas, Hoyos \& Mosquera, 2012) cited by Rivera and Col; (2013).

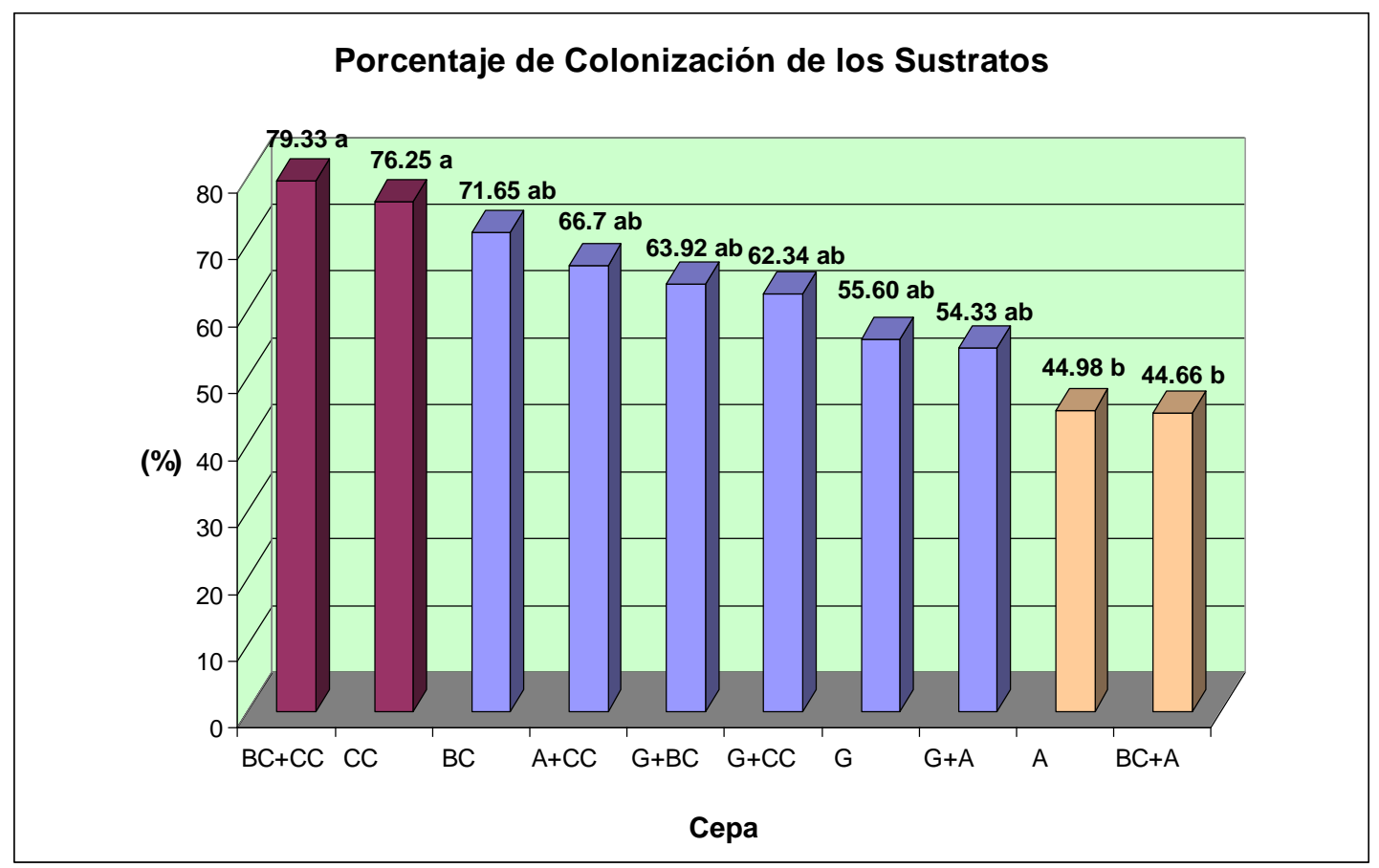

Averages with a common letter are not significantly different ( $\mathrm{p}>0.05)$.

$\mathrm{A}=$ Sawdust, $\mathrm{G}=$ Grass, $\mathrm{BC}=$ Sugarcane Bagasse, $\mathrm{CC}=$ Coconut Cachaça

Figure 4.2. Colonization Percentage Ratio of Edible Mushroom Strains.

\subsection{Number of Outbreaks of Mushroom Strains}


Analysis of variance for the number of sprouts indicates that there are highly significant differences $(\mathrm{P} \leq 0.05)$ between the edible fungal strains and the evaluated substrates and a significant difference in the strain $\mathrm{x}$ substrate interaction in relation to Pleurotus production (Annex 2). The Tukey Test shows that Pleurotus florida (PFL-216) obtained the highest number of shoots compared to the other strains (10.12 shoots), while Pleurotus ostreatus obtained the least number of shoots (Figure 3.3).

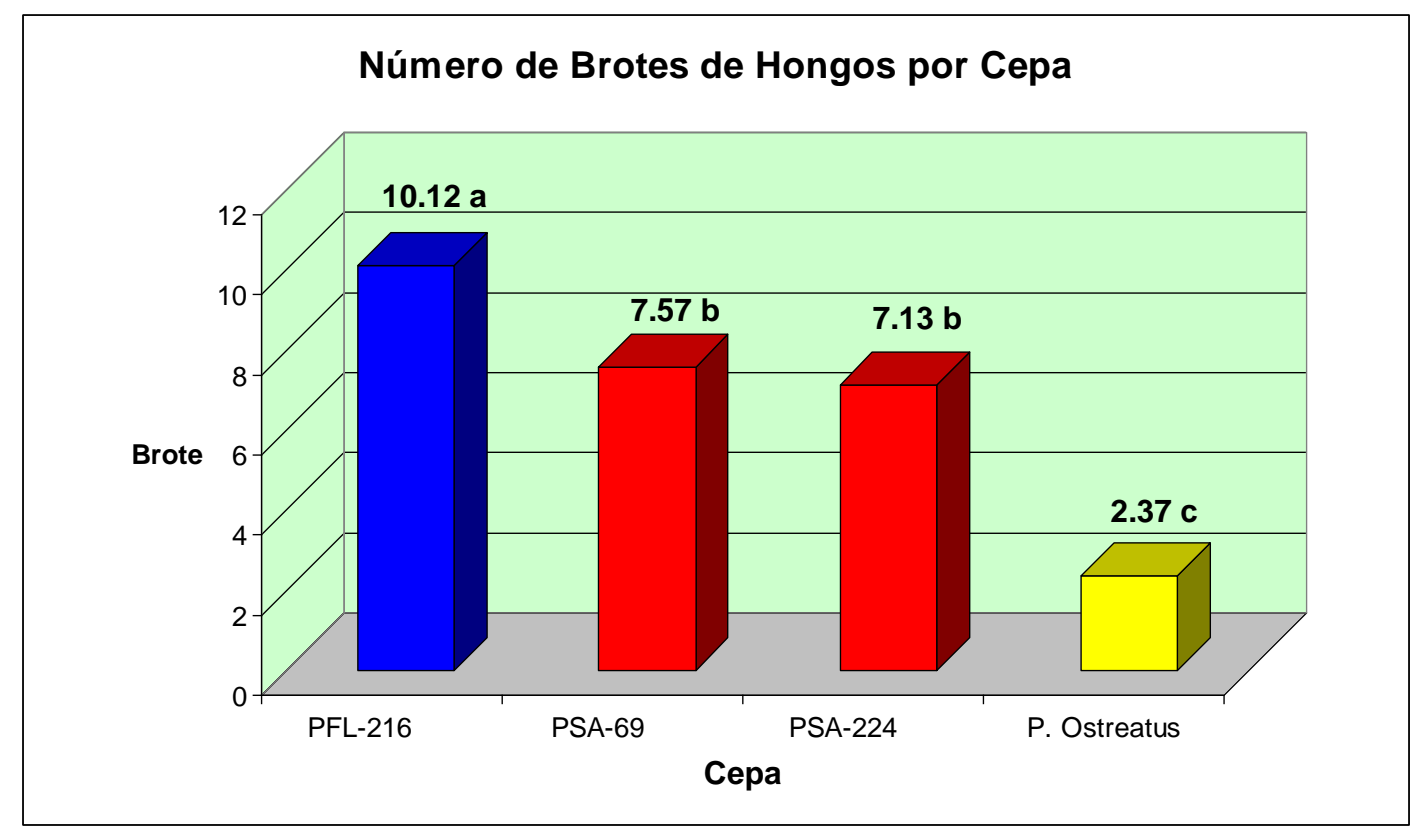

Averages with a common letter are not significantly different $(\mathrm{p}>0.05)$.

PFL-216=Pleurotus florida PSA 224=Pleurotus sapidus PSA-69=P. florida+P. Sapidus

Figure 3.3 Relationship of the Number of Canisters of Mushrooms Produced by Strain.

In the substrates the highest average of fungal outbreaks was obtained with the combination of Grama + Cane Bagasse (11.42 outbreaks) followed by Cane Bagasse with 9.38 outbreaks, while they obtained statistically similar means $\mathrm{G}, \mathrm{A}$ and $\mathrm{G}+\mathrm{A}$ with $7.42,7.21$ and 7.0 respectively. The lowest number of outbreaks were obtained with substrates $\mathrm{G}+\mathrm{CC}, \mathrm{BC}+\mathrm{A}$, and $\mathrm{CC}$ with means of 4.46, 4.17, and 4.04 (Figure 3.4). 


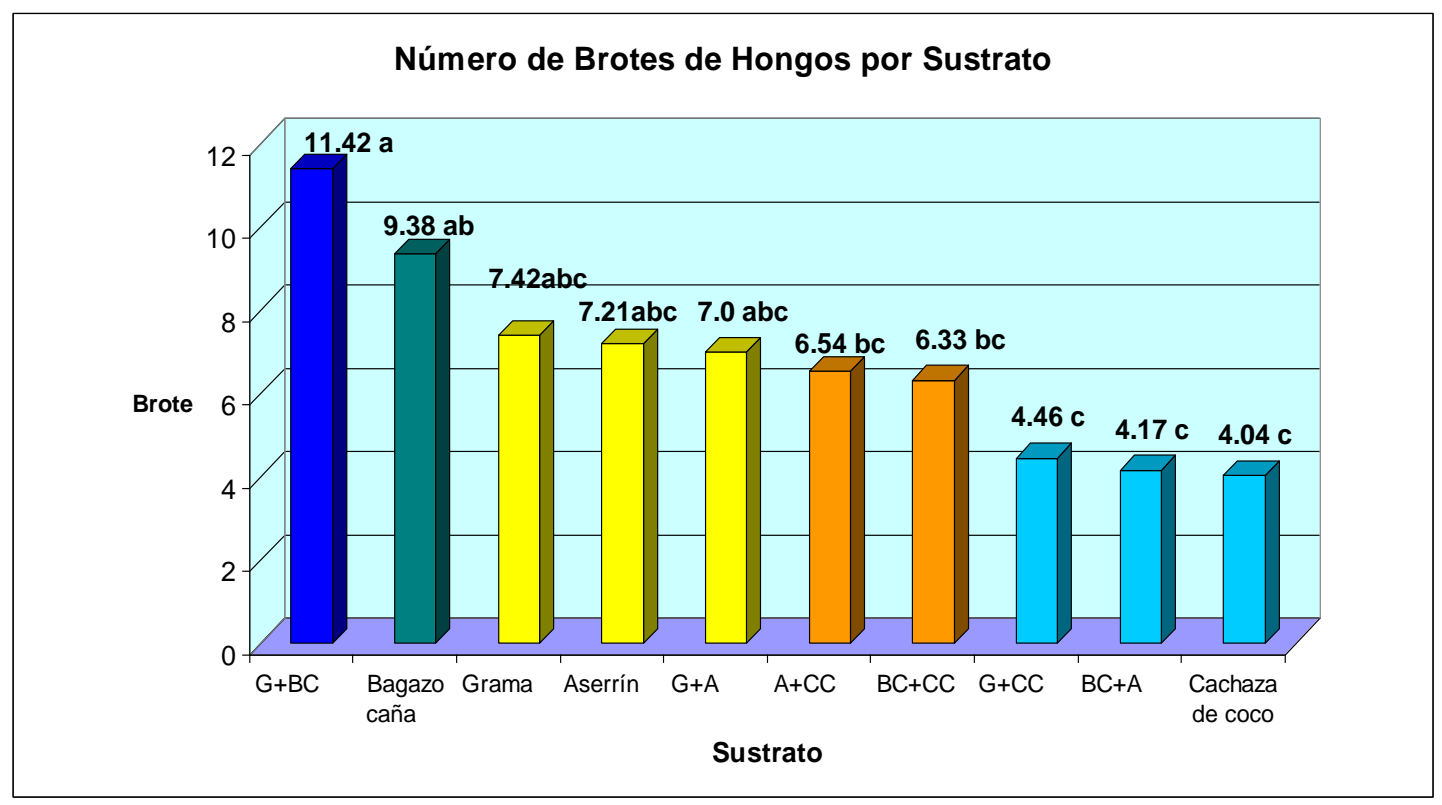

Averages with a common letter are not significantly different ( $p>0.05)$

$\mathrm{A}=$ Sawdust, $\mathrm{G}=$ Grass, $\mathrm{BC}=$ Sugarcane Bagasse, $\mathrm{CC}=$ Coconut Cachaça

Figure 3.4. Relationship of the Amount of Shoots produced in the Substrates.

In the strain $\mathrm{x}$ substrate interaction, the best combination to obtain the greatest number of fungal shoots was with the Pleurotus sapidus strain (PSA-69) and the Grama + Bagasse de Caña substrate with 16.0 shoots, while with the Pleurotus ostreatus strain and the Grama + Sawdust and Grama + Coconut Cachaça substrates had the lowest number of shoots of 1.83 and 1.33, respectively.

\subsection{Mushroom yield}

The results of the analysis of variance and the Tukey test indicate that there are significant differences between the strains of fungi for performance, while there are highly significant differences between the means of the substrates and the strain $\mathrm{x}$ substrate interaction. Strains Pleurotus florida (PFL-216) obtained the highest yield of fungi $(64.70 \mathrm{~g})$ followed by Pleurotus sapidus (PSA-224), Pleurotus ostreatus and PSA-69 (Pleurotus florida + Pleurotu sapidus) which were statistically similar with 53.3, 55.55 and $54.53 \mathrm{~g}$ ), respectively (Figure. 3.5). 


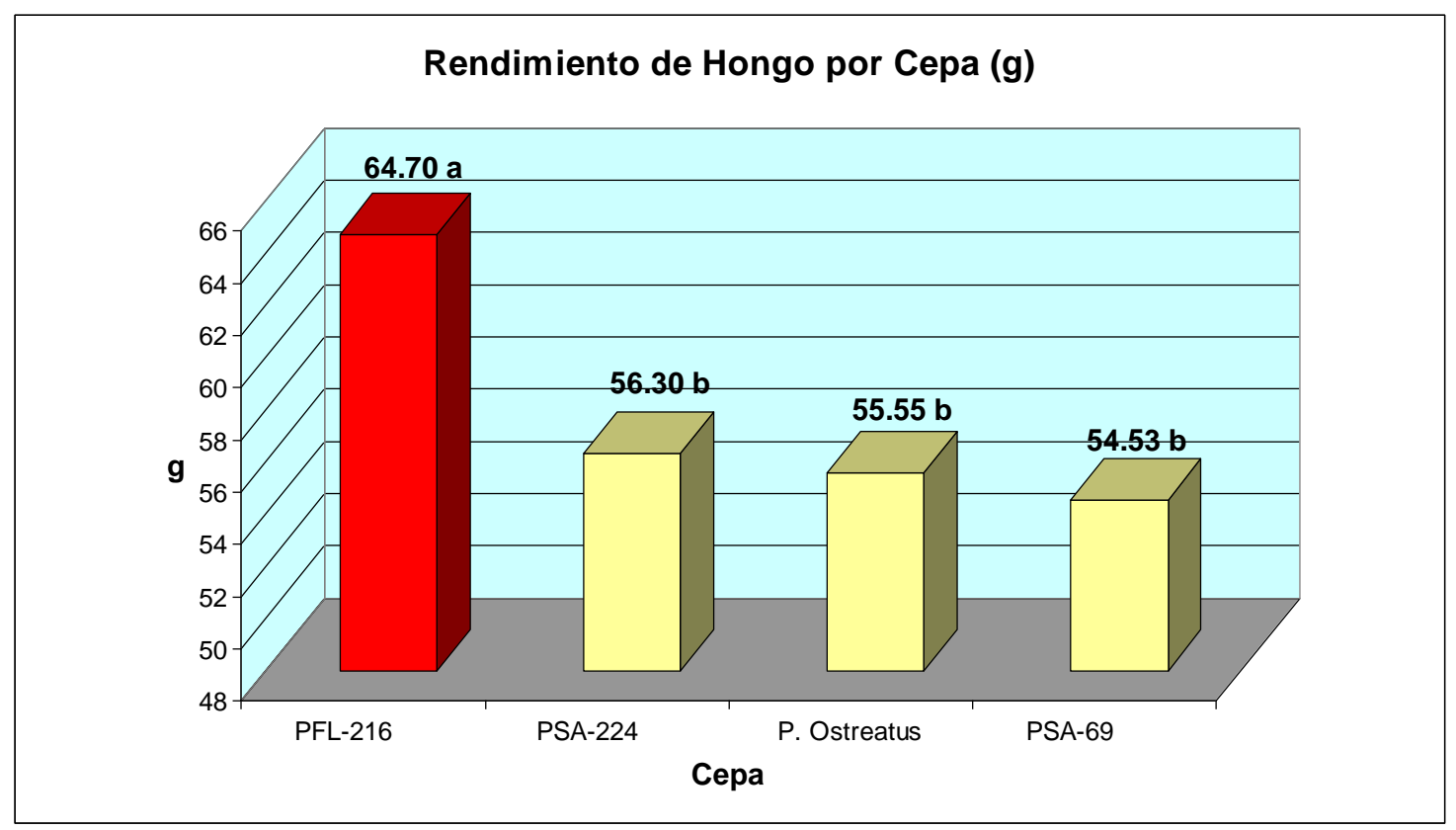

Averages with a common letter are not significantly different $(p>0.05)$

PFL-216 = Pleurotus florida PSA $224=$ Pleurotus sapidus PSA-69 = P. florida + P. sapidus

Figure 3.5 Yield Ratio of Mushroom Strains.

In the use of agro-industrial substrates for the production of edible mushrooms, yield averages were recorded from 36.18 to 68.88 grams, with the highest and lowest yield corresponding to Cane Bagasse and Coconut Cachaça, respectively (Figure 4.6). Regarding the Strain x Substrate interaction, the highest fungus yield was obtained using the PSA-224 strain (Pleurotus sapidus) using the Cane Bagasse with a yield of 126.78 grams, while the lowest yield was achieved with the PFL-216 (Pleurotus florida) using coconut Cachaça with an average of 23.63 grams.

Averages with a common letter are not significantly different $(p>0.05)$

$\mathrm{A}=$ Sawdust, $\mathrm{G}=$ Grass, $\mathrm{BC}=$ Sugarcane Bagasse, $\mathrm{CC}=$ Coconut Cachaça 


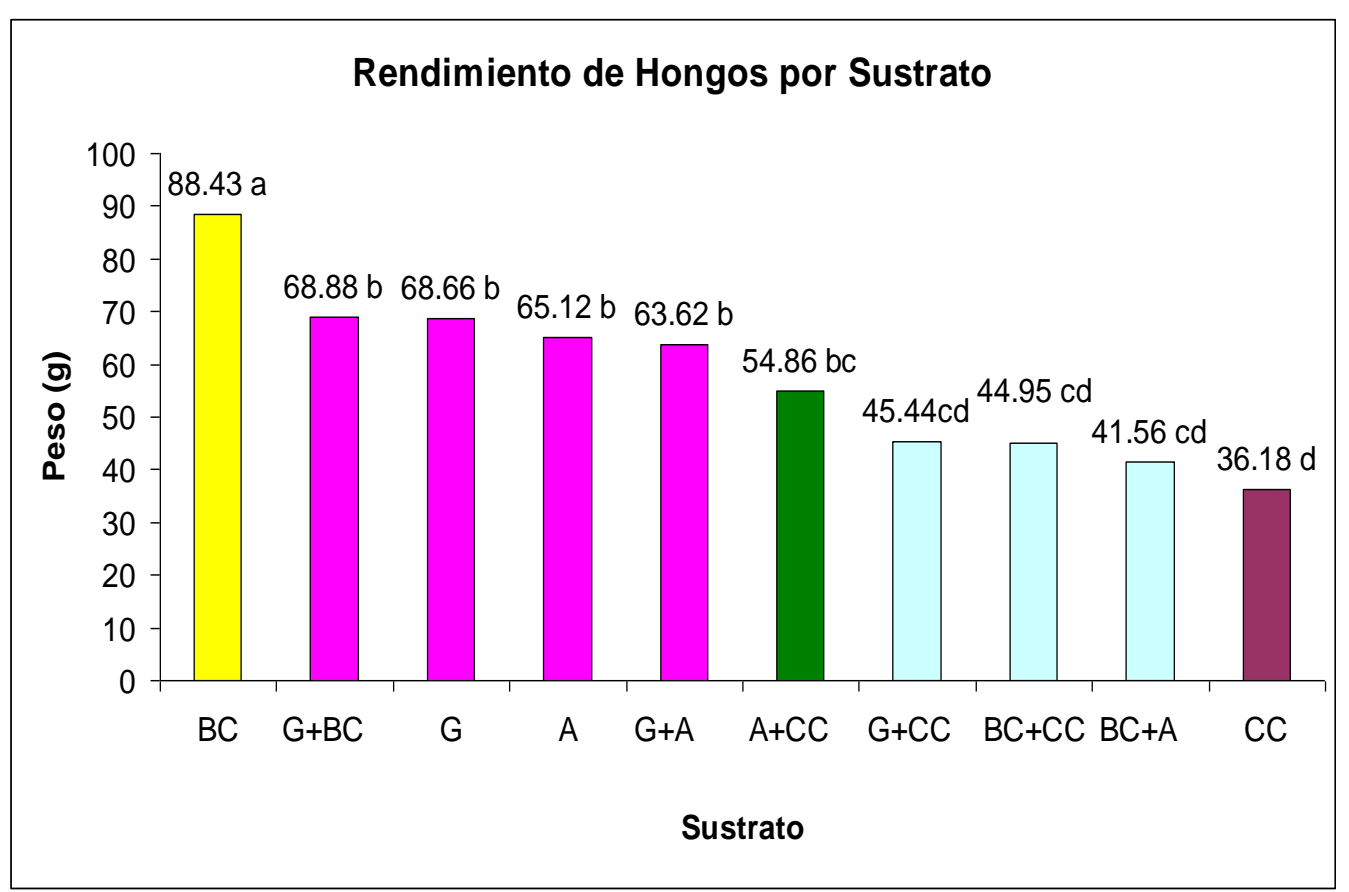

Figure 3.6 Relationship of Mushroom Yield in Different Substrates.

Mondal, (2010) in

Bangladesh worked with the Pleurotus florida oyster mushroom with different substrate compositions (banana leaves and rice straw) finding the highest biological efficiency and the highest economic yield (164.4 $\mathrm{g}$ and $151.1 \mathrm{~g})$ from straw of rice which exceeded the results of the present investigation.

\subsection{Biological Efficiency}

The biological efficiency determines the biological potential of the substrates for the production of fungi. Statistical analyzes showed highly significant differences between fungal strains, substrates and Strain x Substrate interaction.

In this investigation, the Pleurotus florida (PFL-216) and Pleurotus sapidus (PSA-224) strains presented the highest percentages of biological efficiency with 47.23 and 42.22 , being statistically similar. The strains Pleurotus ostreatus and Pleurotus florida + Pleurotu sapidus (PSA-69) followed also with statistically similar means with 36.0 and $31.0 \%$ (Figure 3.7). 


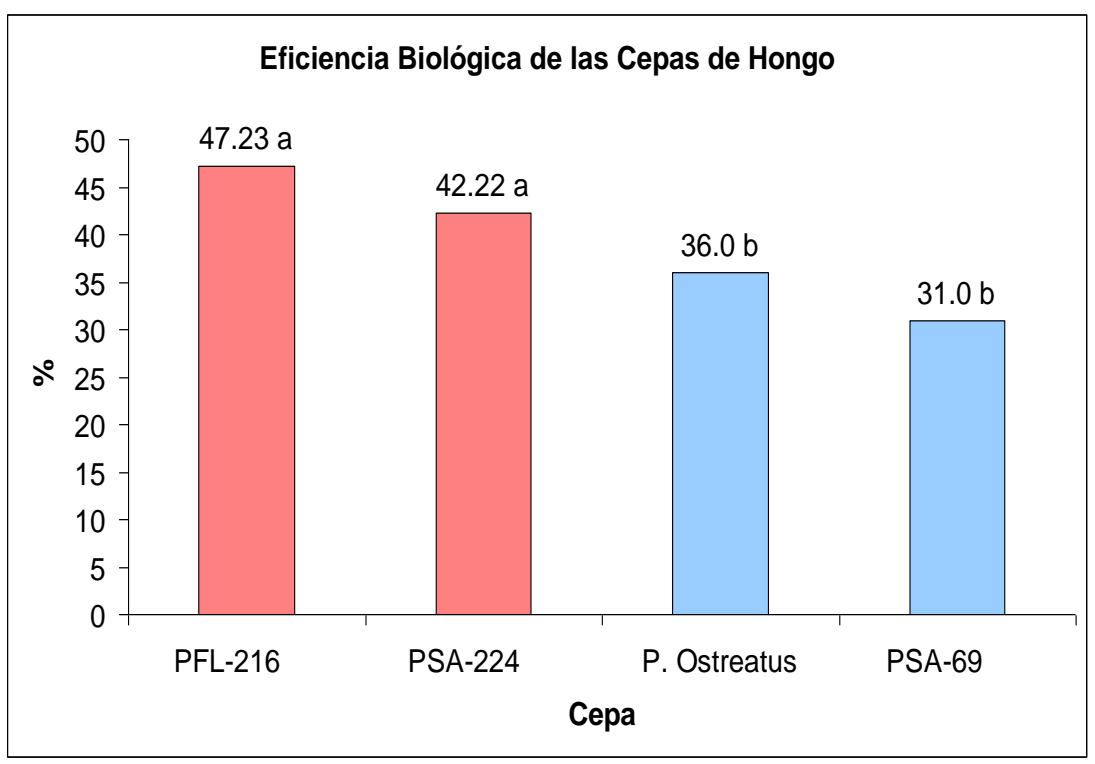

Averages with a common letter are not significantly different $(\mathrm{p}>0.05)$

PFL-216 = Pleurotus florida PSA 224 = Pleurotus sapidus PSA-69 = P. florida + P. Sapidus

Figure 3.7 Relationship of Biological Efficiency among Strains of Fungi.

The most efficient substrate for the production of edible fungi was the Cane Bagasse with the highest biological efficiency (61.33\%) followed by the Grama (52.27\%), while the Cachaza de Caña substrates with the lowest biological efficiency and the combination of Cane Bagasse + Sawdust with 25.65 and $25.15 \%$, respectively (Figure 3.8).

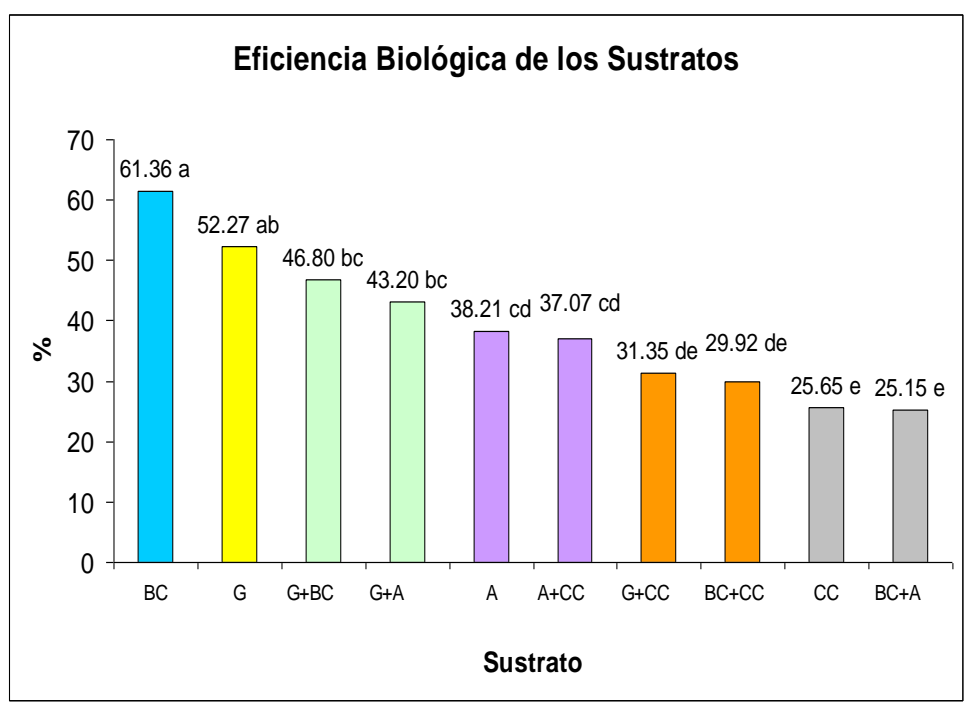

Averages with a common letter are not significantly different $(\mathrm{p}>0.05)$

$\mathrm{A}=$ Sawdust, $\mathrm{G}=$ Grass, $\mathrm{BC}=$ Sugarcane Bagasse, $\mathrm{CC}=$ Coconut Cachaça 
Vol. 5, No. 04; 2020

ISSN: $2456-8643$

Figure 3.8 Relationship of the Biological Efficiency of the Substrates in the Production of Edible Mushrooms.

The Strain $x$ Substrate interaction indicates that the highest biological efficiencies in the production of fungi were obtained with the Pleurotus sapidus (PSA-224) strains using Cane Bagasse and Pleurotus florida using Grama with values of 99.82 and $96.74 \%$, followed by Pleurotus florida with the combination Grama + Sawdust with an average of $68.97 \%$. The lowest biological efficiencies were obtained using the PSA-69 strain (Pleurotus florida + Pleurotu sapidus) using the Bagazo de Caña + Cachaza de Coco, Cachaza de Coco Y Grama + Sawdust substrates with averages of $16.07,15.75$ and $15.66 \%$.

According to Cardona, (2001), Ríos and Col; (2010), cited by Díaz and Col; (2014), the low rates of biological efficiency are attributed to the depletion of nutrients in the substrate and the way in which each seed assimilates them, as well as the origin of the same, factors that directly influence the production of carpophores.

Cuevas y Col; (2014) in Cuba, evaluated agricultural residues for the production of the fungus Pleurotus ostreatus and concluded that the residues of lentil, sugarcane bagasse and barley straw used in the cultivation of the fungus presented the highest biological efficiency values (113, 96 and $84 \%$, respectively), these values being higher than those of the present investigation although in different substrates.

In previous investigations carried out in works developed within the Project of "Collection, domestication, cultivation and production of native fungi" that is developed in the Science Subarea Chemists from the Faculty of Agronomy of the University of San Carlos de Guatemala, a series of substrates have been classified as "good or adequate" such as coffee pulps and African palm fibers; "Regular or inadequate" such as the remains of grass crops and the "bad or inadequate", mainly constituted by mulches (plant remains of the forest), according to what reported in the studies of García (2000), Girón (2000), Rojas (2004) and Garcés (2005), cited by Calderón, (2009), based on the biological efficiency of the Pleurotus ostreatus strains that have been evaluated. Thus, materials that have 100 percent or more biological efficiency are considered good or adequate, between $80-99$ percent are fair or poorly suited, and less than 80 percent are poor or unsuitable.

Nitrogen supplementation with urea presents an option to make use of substrates classified as fair or poor, as they present a low biological efficiency, which is supposed to be caused by the high carbon-nitrogen ratio. However, these are abundant, available and low-cost materials that, when enriched with nitrogenous supplements, are expected to improve the biological efficiency of the aforementioned fungus, as the Monterroso study indicates, that urea has a positive effect on the biological efficiency of Pleurotus ostreatus (Calderón, 2009).

García Ramos (2000) cited by Calderón (2009), evaluated corn stubble and rice husk individually and their mixtures in three different proportions (1:1,2:1 and 1:2), using a completely at random, with six treatments and eight repetitions at the rate of 1 pound of substrate in dry weight per experimental unit. The best yield in weight and biological efficiency was obtained with the 2: 1 mixture of corn stubble and rice husk, respectively, with a biological 
Vol. 5, No. 04; 2020

ISSN: $2456-8643$

efficiency of 117.3 percent and an average weight of 532.5 grams per experimental unit. The biological efficiency of the coffee pulp control was 105.5 percent and a total weight of 479 grams per unit. Concluding that the use of mixtures of corn stubble and rice husk is preferable to the use of these same unmixed substrates.

\section{CONCLUSIONS}

Bagazo de Caña and Cachaza de Coco substrates obtained the highest colonization percentages (79.33 and 76.25\%). The other substrates obtained statistically similar means except the substrates Sawdust and Bagasse of Cane + Cachaça de Coco that obtained the lowest colonization percentages of 44.98 and $44.66 \%$.

With the Pleurotus florida strain (PFL-216), the highest shoot yield was obtained (10.12), while in the substrates used $\mathrm{G}+\mathrm{BC}$ achieved the highest number of shoots (11.42).

The highest yield of fungi (88.43 g) was obtained with sugarcane Bagasse, in the same way in the strain $\mathrm{x}$ substrate interaction the highest yield was obtained with the Pleurotus sapidus strain (PSA-224) and the sugarcane Bagasse with $126.78 \mathrm{~g}$.

The Pleurotus florida strain (PFL-216) and PSA-224 were the ones that best adapted to the controlled environmental conditions of the research, with a higher biological efficiency than the other treatments (47.23 and $42.22 \mathrm{~g}$ ).

The substrates generated from the agro-industry are considered as a good option to be used in the cultivation of edible mushrooms, especially the combinations between them due to the greater production of carpophores obtained, as well as the biological efficiency.

This type of project could be adapted to the needs of rural family production systems, favor the appropriate balance with agricultural and extra-agricultural activities, in addition to providing income, work opportunities and food (protein intake) to the population. However, to achieve this, it is necessary to implement training to publicize cultivation techniques for this species in highyield substrates.

\section{REFERENCE}

Ahmed, M .; Abdullah, N .; Ahmed, K.U .; Bhuyan, M.H.M.B. 2013. Yield and nutritional composition of oyster mushroom strains newly introduced in Bangladesh. Pesquisa Agropecuaria Brasileira 48: 197-202.

Baldrian, P. \& Valásková, V. (2008). Degradation of cellulose by Basidiomycetous Fungi. FEMS Microbiol. Rev. 32: 501-521.

Caicedo, Pilin Manyoma. (2013). Use of Organic Lignocellulosic Residues from Industrial Activities for the Production of Edible Fungi Pleurotus spp. In the Special District of Buenaventura, Colombia. Degree Project to Qualify for the Title of Environmental and Natural Resources Administrator. Universidad Autónoma de Occidente Faculty of Basic Sciences 
Vol. 5, No. 04; 2020

ISSN: $2456-8643$

Department of Environmental Sciences Program of Environmental Administration and Natural Resources Santiago de Cali, Colombia.

Calderón Mérida, J. A. (2009). Determination of the best Stage of Application of Nitrogen Fertilization in the Substrate of Corn Cane (Zea mays L.) for the Production of the Mushroom Pleurotus ostreatus (Jacq.) Kumm (Strain ECS-152) ”. University of San Carlos of Guatemala.

Cuevas, Ruilova; Bernarda, María. and Hernández Monzón, Aldo. (2014). Evaluation of Agricultural Residues for the Production of the Mushroom Pleurotus ostreatus ICIDCA. On the Sugar Cane Derivatives, vol. 48, no. 1, January-April, 2014, pp. 54-59 Cuban Institute for Research on Sugar Cane Derivatives. Havana City, Cuba.

Cury R, Katia1 M.Sc. Aguas M, Yelitza1 M. Sc, Martinez M, Ana Esp, Olivero V, Rafael M.Sc, Chams Ch, Linda. (2017). Agroindustrial Waste its Impact, Management and Use. Colombian Journal of Animal Science. 2017; 9 (Suppl): 122-132. DOI: 10.24188 / recia.v9.nS.2017.530.

Díaz C. Claudia and Carvajal R. Eduardo. (2014). Biological Efficiency of Pleurotus ostreatus Grown in Oil Palm Fiber. Universidad de Santander- UDES, Bacteriology and Clinical Laboratory, Avenida 4a, Esquina Calle 10 Norte. Cúcuta, Norte de Santander. Colombia.

Estrada, A.E.R .; Jimenez-Gasco, M.M ; Royse, D.J. 2010. Pleurotus eryngii species complex: sequence analysis and phylogeny based on partial EF1 $\alpha$ and RPB2 genes. Fungal Biology 114: 421-428.

García-Oduardo, C. Nora; Bermúdez-Savón, C. Rosa Catalina and Serrano-Alberni Migdalia. (2011). Substrate Formulations in the Production of Edible Pleurotus Mushrooms. Industrial Biotechnology Study Center (CEBI), Universidad de Oriente, Santiago de Cuba.

Heredia-Solis, A; Esparza-Ibarra, E; Romero-Bautista, L; Cabral-Arellano, F. and BañuelosValenzuela, R. (2014). Bagasse from Agave Salmiana and Agave weberi Used as Substrate to Produce Pleurotus. Biotechnology Laboratory. Autonomous University of Zacatecas. Mexico. Iberoamerican Science Magazine ISSN 2334-2501 Vol. 1 No.5.

Hernández, Rodolfo Leben. (2004). Medicinal and Nutritional Properties of Edible Mushrooms. Mexico. Esoterika Library. http://www.gftaognosticaespiritual.org.

Koutrotsios, K.C. Mountzouris, I. Chatzipavlidis and Zervakis, G.I. (2014). Bioconversion of Lignocellulosic Residues by Agrocybe cylindracea and Pleurotus ostreatus Mushroom fungi Assessment of their Effect on the Final Product and Spent Substrate Properties. Food Chemistry, Vol. 161, pp. 127-135.

Márquez, Lissete Albán (2018). Cultivation of the Oyster Mushroom (Pleurotus ostreatus) in Three Types of Residues from the Wood of Bolaina Blanca (Guazuma crinita). La Molina National Agrarian University Faculty of Forest Sciences. Lima Peru. Thesis to Opt for the Title of Forest Engineer. 
Vol. 5, No. 04; 2020

ISSN: 2456-8643

Martínez Cañedo, Jesús. (2012). Cultivation of Pleurotus ostreatus in the Valle de el Fueerte, Sinaloa: an Alternative for the Use of Agricultural Esquilmos. Thesis to Obtain the Degree of Doctor of Science. Autonomous Indigenous University of Mexico.

Martínez, Y; garzón, C Pedro; Hainaut, E; john E .; Guarnizo, F. Wilder, Anderson, (2008). Evaluation of the production of the fungus Pleurotus ostreatus Cultivated on the Residues Derived from the Commercial Production of the Culm of Guadua angustifolia Kunth. Chemistry Program, University of Quindío. Tumbaga Magazine 3, 43-53.

Mondal, S. R; Rehana, M. J; Noman M. S. and Adhikary S. K. (2010) .Comparative Study on Growth and Yield Performance of Oyster Mushroom (Pleurotus florida) on Different Substrates. Agrotechnology Discipline, Khulna University, Khulna-9208, Bangladesh.

Nevárez Quiñones, Daniela Margarita. (2012). Use of Agroforestry Residues for the Cultivation of Edible Fungi (Pleurotus sp.). Thesis to obtain the degree of: Master of Science in Environmental Management. National Polytechnic Institute Interdisciplinary Research Center for Integral Regional Development Durango Unit.

Omarini, Alejandra; Albertó, Edgardo O. and Zygardo, Julio. (2009). Intensive production on lignocellulosic waste, nutritional analysis and organoleptic qualities of Polyporus tenuiculus (Polyporaceae, Basidiomycetes): Biodeterioration and Biotransformation of the substrate. Thesis to Opt for the Doctorate in Molecular Biology and Biotechnology. National University of San Martín. Biotechnological Research Institute (IIB).

Ramos, Irene Roncero. (2015). Nutritional and Healthy Properties of Mushrooms. La Rioja Mushroom Research Technology Center (CTICH).

Redin Iroz, Maia. (2010). Effect of Induction with Aqueous Extracts of Wheat Straw on the Production of Lignolytic Enzymes in Pleurotus ostreatus. Public University of Navarra. Higher Technical School of Agricultural Engineers.

Ríos-Ruiz, Winston Franz; Valdez-Núñez, Renzo Alfredo; Jiménez-Flores, Juan Pablo. (2017). Isolation, Propagation and Growth of Native Edible Fungi in Agro-industrial Waste. Laboratory of Agricultural Microbiology, Faculty of Agrarian Sciences, National University of San Martín Tarapoto, Jr. Maynas 177, Tarapoto, San Martin, Peru.

Rivera-Omen, R. L., Martínez-Mamián, C. A. \& Morales-Velasco, S. (2013). Evaluation of agricultural residues as a substrate for the production of Pleurotus ostreatus. Blue Moon Magazine, 37, 89-100. $\quad$ Recovered from http://lunazul.ucaldas.edu.co/index.php?option=content \&task=view\&id=847

Rodríguez, Gustavo E; Martínez, Daniel A; Buglione, María B; Filippi, Marcela V. \& Agüero, Susana M. (2018). Culture of Pleurotus Ostreatus (Jacq .: Fr.) Kummer on Pomace: Evaluation of the Productivity and Chemical Composition of the Biodegraded Substrate. Laboratory of Edible and Medicinal Mushrooms. Faculty of Agrarian Sciences, National University of Comahue. Argentina. Annals of Biology 40: 21-30, 2018 DOI: http://dx.doi.org/10.6018/analesbio.40.03 
Saval, S. (2012). Use of Agro-industrial Waste: Past, Present and Future. Journal of the Mexican Society for Biotechnology and Bioengineering A.C. ISSN 0188-4786. (16): 14-46.

Varnero, María T; Quiroz, Madelaine S. and Álvarez, Cristian H. (2010). Use of Lignocellulosic Forest Residues for the Production of the Oyster Mushroom (Pleurotus ostreatus). University of Chile, Faculty of Agronomic Sciences, Box 1004, Santiago-Chile. Technological information. Vol. 21 (2), 13-20 doi: 10.1612 / inf.tecnol.4154it.09

Zheng, Z. \& Shetty, K. (2000). Solid-State Bioconversion of Phenolics from Cramberry Pomace and Role of Lentinula edodes $\beta$-Glucosidase. J. Agric. Food Chem. 48: 895-900. 